\title{
The Reduction of Natural Disasters
}

Disasters take about 250.000 lives and cause US\$40 billion in damage each year. Human suffering and economic losses have been rising during the last two decades. Humankind is becoming increasingly vulnerable because development concentrates population, infrastructure, and economic resources. By its resolution 44/236, of December 22, 1989, the General Assembly of the United Nations proclaimed the Decade for Natural Disaster Reduction, beginning January 1, 1990. The International Framework of Action sets goals, policy measures to be taken at the national level, and action to be taken by the United Nations system. The organizational arrangements include a Special High-Level Council, a Scientific and Technical Committee, and a Secretariat, with financing from extrabudgetary resources through a trust fund. There is a considerable level of national participation-seventy-two national committees or focal points have been established. The overall objective of the Decade is to prevent-or mitigate-natural disasters worldwide. Global and regional efforts must be mobilized to bring to bear the latest understandings and advancements in science and technology on natural disaster prevention. Strategies to mitigate natural hazards require planning and building to withstand a hazard, identifying and avoiding the sites where hazards are likely, predicting the occurrence of hazards, and preventing or altering a hazard's characteristics. Effective measures require understanding of the fundamental causes of disasters, of the nature of their effects, and of techniques for coping with the effects. Encouraging research and development and bringing to bear its results are integral aspects of the decade. Coupled with this objective is the absolute necessity for education and training of scientists and engineers who must carry out this work. (Ed.)

\section{The costs of disasters and the benefits of disaster reduction}

According to the World Bank, disasters take about 250,000 lives worldwide each year and cause about US $\$ 40$ billion in physical damage. Wind storms, floods, and earthquakes alone cost an average US $\$ 18.8$ million per day. The impact of disasters is disproportionately high on the developing countries, with the losses to GNP due to disasters being about twenty times greater there than in more developed countries. The consequences include deepening the cycle of poverty, increasing the susceptibility to further disasters, and creating disincentives for investment and development. The need for action is further underlined by the fact that the world population is estimated to increase by over 950 million between 1990 and 2000 (to 6.25 billion) and that over 900 million of this increase is projected to take place in the developing world.

The benefits of disaster reduction will result from the mitigation of their negative effects on society and will be of two kinds: (1) the protection of lives, physical integrity, and overall well-being of the population; and (2) the protection of the physical infrastructure essential to social and economic development and of the regular functioning of the economic system. Both kinds of benefits are vital to the safeguarding of society.

While human suffering and economic losses due to natural disasters have been rising considerably during the last two decades, sufficient reliable data on the impacts of disasters do not exist. Such impacts should be documented, including data on the direct expenditure needed to restore, or attempt to restore, conditions existing before disasters and the losses through slowdown in economic activity in the short term and impairment in the long term. The true cost of the tragic loss of human lives cannot be estimated, but the costs of the loss of their skills and economic contributions should be quantified, as human beings are the true basis of development as well as its beneficiaries. The development of a broad-based disaster-history database is a challenging task that will require effort by the UN system as well as from outside, for example, from the private sector (insurance companies). Such data are important to decisionmaking in regard to the investments that disaster prevention requires.

\section{The causes}

The dynamic processes of the Earth make it a habitable planet; however, they also make it a hazardous place in which to live. The geologic forces that cause earthquakes, volcanic eruptions, and landslides on the one hand threaten human lives and assets, but on the other hand they build the mountains, replenish the soils, and shape the landscape. The atmospheric forces that bring storms flood the land, but they also nourish the crops. Coping with these natural forces is a continuing challenge for mankind.

"Vulnerability" is a concept that includes not only the likely magnitude of the forces but also the lives and property at risk. Population growth, industrialization, and urbanization increase the exposure of lives and property to natural hazards and hence the likely cost in human and economic terms. Humankind in fact is becoming more and more vulnerable because development concentrates assets - of population, of physical infrastructures, of economic resources - in an increasingly complex and valuable system. Increases in population, economic deprivation, and accelerating requirements for the use of Earth's natural resources generate pressures to move into areas more subject to disasters. Thus poverty also increases vulnerability. Humanity's increasing exposure leads to an increasing 
impact of natural disasters in terms of loss of life, physical damage, and the detrimental effects on the economic and social development of vulnerable countries.

\section{Natural and man-made disasters}

United Nations General Assembly resolution 44/236, in setting out the objective for the International Decade for Natural Disaster Reduction, gave as examples of natural disasters to be addressed, earthquakes, windstorms, tsunamis, floods, landslides, volcanic eruptions, wildfires, grasshopper and locust infestations, and drought and desertification.

While natural forces primarily cause such disasters, human intervention frequently increases the vulnerability of the affected ecosystems and the natural resources base, thereby increasing the risk. Increasingly, it has to be recognized that natural forces are at work in a planet whose environment is being modified by humankind. Flooding and indeed the drought/flood cycle are made more severe by deforestation. Increases in energy retention by the Earth owing to greenhouse gases, and consequent global warming, may well manifest themselves in a great increase in the number, severity, and even type of natural disasters. For example, a rise in sea level will increase the likelihood of flooding in coastal areas. More generally, increased violence and seasonal and geographic displacement of tropical storms, sea surges, sea-level rise and delta flooding, salinization of coastal aquifers, changes in vegetation zones with possible changes in desertification patterns, to name only some effects, may be anticipated. Global environmental change is today a major issue. The effects of humankind on nature and of nature on humankind interact. It therefore makes sense to examine natural disasters and their effects in terms of a spectrum covering natural forces and human intervention.

Environmental degradation, as it attacks the resource base upon which humankind, and indeed all living things, depend for their sustenance, vitiates the capacity for long-term development, narrows the options, and destroys the inheritance of future generations. That is a familiar line of argument. Implicit in the environmental argument or in much of it has been the long time horizon. Environmental degradation has been characterized as a creeping disaster. But now environmental concerns take on a fresh urgency. Hazardous wastes and nuclear accidents are not creeping disasters. The arguments in regard to climate change are that even where the disaster may be creeping in its pace of visible impact, solutions now require urgent action, and the same applies to the ozone layer and to other environmental problems.

Natural disasters, on the other hand, have been seen as fast moving or rapid onset disasters. However, preventing or mitigating such disasters requires time and depends on understanding the natural forces at work. Thus progress in, for example, the atmospheric and Earth sciences helps develop measures that may help us predict, warn, and prepare better. That very progress also helps us to understand the forces at work that influence impacts on the environment, for instance the interaction between oceans and atmosphere. Dealing with environmental concerns and with natural disaster concerns requires mobilizing the same pool of knowledge and fostering its advance.

Management measures. 100 , have a share of commonality. Warnings and preparedness for industrial accidents may have much in common with warnings and preparedness for natural disasters, although the bell ringers may be different. The need to conserve and manage watersheds is the same, whether the concern is environmental degradation or flooding seen as a natural disaster. What is important is to address them effectively.
Possibly, that is why the forty-fourth session of the UN General Assembly also adopted a resolution, 44/224, on international cooperation in the monitoring, assessment, and anticipation of environmental threats and on assistance in case of environmental emergencies. This resolution refers to potential environmental disasters, whether natural, accidental, or caused by human beings, just as the resolution on the Decade recognized the importance of environmental protection for the prevention and mitigation of natural disasters.

\section{Early warning}

An important aspect of a "prevention-is-better-than-cure" approach is the ability to assess risks and provide early warnings and to have them believed and acted upon. In regard to natural disasters, the actions required vary depending upon the particular phenomena. There is, however, a broader context to early warning, and this is that there are interactions between different categories of emergency situations and hence between early warnings.

Thus in many cases an early warning of the environmental degradation, for example, in regard to deforestation may be important to assessing the proneness to landslides. Early warning of certain kinds of economic crises and understanding of impacts may point to population movements that increase proness to various kinds of natural phenomena. The opposite also holds true. The examples can be multiplied. What is clear is that we are seeing in operation an interactive system in which economic, political, environmental, population, and natural disaster situations interact and can cascade to create situations of stress and emergency and the spasms of crisis. The results of the crises are seen in terms of human lives lost, refugees and displaced persons, economic resources lost or degraded, and the setting into motion of vicious cycles deepening human misery. Security on Planet Earth begins to acquire a new dimension.

\section{Proclamation of the International Decade for Natural Disaster Reduction and consequent actions}

$B_{y}$ its resolution 44/236, of 22 December 1989, the General Assembly proclaimed the Decade for Natural Disaster Reduction, beginning 1 January 1990, and adopted an International Framework of Action. This Framework sets objectives and goals, policy measures to be taken at the national level, and action to be taken by the United Nations system. The organizational arrangements during the Decade, for which provision was also made in the Framework, include a Special High-Level Council, a Scientific and Technical Committee, and a Secretariat, with financing from extrabudgetary resources through a Trust Fund. In a progress report to the General Assembly at its current, forty-fifth, session, the Secretary-General has reported on action taken to implement the resolution. The report shows very considerable activity at the national level, with the establishment of seventy-two national committees or focal points, and the setting in train of a number of meetings and conferences giving visibility to the Decade and generating approaches to its implementation at the national and international level. The report also shows that the UN system is actively engaged with special efforts by United Nations Disaster Relief Coordinator: World Health Organization; World Meteorological Organization; United Nations Educational, Scientific, and Cultural Organization; Food and Agriculture Organization; United Nations Development Programme; Economic and Social Commission for Asia and the Pacific; and the World Bank, each of which is developing specific plans and projects in regard to the 
Decade. The previously-established UN Steering Committee to coordinate UN system activities, which is chaired by the Director-General for Development and International Economic Cooperation, has had its mandate renewed by the Secretary-General and will play a critical role.

\section{The approach}

The overall objective of the Decade is to prevent-or to mitigate, which is in a way the same object - natural disasters worldwide. The Decade is predicated upon the idea that countries must mobilize to meet this objective and that applying science and technology make the attainment of the objective possible. The objective can only be achieved by the efforts of countries themselves. The Decade should inspire them to achieve the objective and help them to acquire or reinforce the means to do so. Effective functioning of national committees, mobilizing all concerned at the national level and giving coherence and purpose to their efforts, is the key. Those concerned are not just the departments of government at the various national, provincial, or local levels. They are also the scientific, professional, business, and industrial communities and those involved in the humanitarian and other nongovernmental efforts through which people act to mobilize their own efforts or to impact on the efforts of others. It is important to augment the role of those likely to be affected by disasters in the decisionmaking process relating to measures to reduce vulnerability. The sharing of experience between national committees is essential. They need to influence the pattern of economic and social development in their countries to avoid or mitigate the gross impacts of disaster as a result of which much of development effort and capacity is lost. They must show how addressing the issue effectively is cost beneficial to national economies. Indeed, efforts to reduce vulnerability may themselves provide a means for development.

An important aspect of disaster mitigation or prevention measures in the economic context is the displacement of the economic cost, mainly through insurance mechanisms, from affected populations at a particular time when disaster occurs to society as a whole over broader periods of time. Humanitarian assistance is another way in which the impact is shared. This special, temporal and social displacement should generate incentives to take preventive measures.

Global and regional efforts must be mobilized in support of national efforts to bring to bear the latest understandings of science and advances in technology in natural disaster prevention. It is important to create and to reinforce monitoring networks globally and regionally, to promote data exchange, and to share assessment techniques that can lead to the identification of the management measures required, including the adequate, early, and credible generation of warnings on potential disaster situations and the willingness and capacity to take effective account of them.

The necessary scientific and technological knowledge is available in a large number of countries to employ more broadly prediction and assessment methods on the basis of a better understanding of the causes and effects of natural disasters. Every country must be able to benefit from research in this area and, at the same time, be encouraged to find its own means of reducing its vulnerability by analyzing the particular risks it faces and formulating the needed strategy.

To achieve the objectives of the Decade, a concerted international effort is needed, in which all, including the most modern and dynamic sectors of society, are called upon to participate-science, telecommunications, banking and insurance, local authorities, voluntary organizations (the Red Cross, in particular), and the information media. An integrated approach is essential to reach the objectives that have been identified: reduction in loss of life, property damage, and social and economic disruption.
The Decade Secretariat should see itself as catalytic in mobilizing the various participants - international, intergovernmental and nongovernmental bodies, scientific and professional communities. and the private sector. Part of its role must be to seek to generate resources in support of the efforts of others within commonly agreed approaches and frameworks.

In the end, the crux of the matter is the cost-benefit evaluation of disaster-mitigation policies that has two main aspects: first, where is it cost effective to make additional investments to protect society from disaster and reduce its vulnerability? And, second, when billions of dollars per year are invested in infrastructures and on longterm capital development, what measures should be taken to make these investments less exposed or more resistant to natural disaster"? In making such evaluations, it should not be forgotten that disasters are statistically certain to happen, though scientific knowledge is not yet adequate to allow specific short-term predictions.

Different countries are vulnerable to different potential natura! disasters or to combinations of them. In regard to causes, the Decade should not seek to concentrate just on those that are easy to address. thus meeting the needs of some and not of others. It must be realized that the state of knowledge and capacity to act, as well as the appropriate level of action. differ in terms of various kinds of natural disasters and geographically as well. Therefore, for different categories of disasters, it will be necessary to generate specific approaches and actions, having in mind the importance of a meaningful reduction of the impact of disasters, a cost-benefit approach, and not just of advancing the state of knowledge.

The main constraints to effective disaster reduction have been identified as:

(a) lacking or low conviction among governmental decisionmakers and planners regarding the value of comprehensive disastermitigation plans;

(b) the shortage of personnel trained in disaster-mitigation techniques and of skilled disaster-preparedness and relief personnel leading to a limited understanding of disaster plans among those who are expected to implement them:

(c) insufficient or inadequate disaster-prevention information in educational programs;

(d) the serious difficulties of maintaining disaster awareness and developing an efficient warning system where disasters are potentially severe but infrequent;

(e) incomplete reliable historical documentation of disasters, their effects, emergency-plan and warning-systems performance, and lessons learned in most developing countries;

(f) the limitation of disaster-planning activities in most developing countries to emergency relief and their exclusion from economic development plans;

(g) limited cooperation for disaster planning and preparedness as well as postdisaster relief among neighboring nations in a region or among nations exposed to similar hazards;

(h) the growth of urban centers leading to population congestion and expansion into disaster-prone areas (for example, flood plains. lowlands, coastal areas, and unstable hill slopes);

(i) limited understanding of the merits and relative cost effectiveness of planning and preparedness measures in the field of disaster reduction; and

(j) individuals' opposition to costs and regulatory restrictions associated with many disaster-prevention measures.

\section{Areas of concentration}

The scope of international action in support of the Decade is very large, so an effort must be made to define areas of concentration, and within these areas concrete goals and targets. whose implementation 
could be monitored. This should be an early priority of the Scientific and Technical Committee. Projects will then need to be defined that would adequately address these goals and help reach the targets and financial support sought for these projects through the Trust Fund or otherwise. Examples of suitable projects were prepared for illustrative purposes and made available at the time of General Assembly consideration of the issue, at the 44th session. Unesco has developed criteria that it would consider applying to new project initiatives within the IDNDR. These are:

- Synergism-The project should have goals and activities that correspond closely with those of an existing program of a Member State or a body.

- Catalyst-The project should serve as a catalyst for fostering the formation of a program for the IDNDR.

- Increased knowledge-The project should produce in the next ten years demonstrable results towards loss reduction.

- Technology transfer-The project should enhance and accelerate the flow of information and experience within and across boundaries.

- Self-reliance-The project should generate greater self-reliance of professionals in a country to conduct investigations and to foster applications of mitigation techniques.

- Existing human resources, experience, and facilities-The project should capitalize on the existing situation.

- New frontiers - The projects should provide access to new information, study areas, and partnerships that might not otherwise be available.

The Unesco approach would clearly be useful in defining overall criteria, and the views of the Scientific and Technical Committee and others concerned would be most helpful.

\section{Building national capacities}

National capacity to deal with the consequences of disasters essentially arose with natural disasters, but it can aid in coping with other kinds of emergencies. Such capacity, while often focused on the governmental response, be it at various levels national or local, must include nongovernmental capacities, the capacities of other organized sectors of society such as business, as well as the response evoked in populations confronted with disasters. Thus, as this capacity is built upon to mitigate and prevent, provision must be made for enhancing the effective participation of all actors. There is however, a qualitative difference in the measures required in meeting a disaster and in preventing it. Mitigation and prevention require the capacity to use science and technology and to take effective measures of the kind that fall in the domains of economic activity or development and of development planning. The question therefore arises whether in many countries there is not urgent need to deliver the message to those concerned and to provide them with suitable training. Delivering the message must mean specific advice on what needs to be done, and training means training to do it. An important aspect is the sharing of experience between those likely to be affected by similar situations either in terms of specific kinds of natural disaster, or in terms of the organizational efforts required. A major international effort is thus required at the regional and global levels to promote training and the exchange of experience. Building national capacity in regard to natural disaster prevention and mitigation will also augment the capacity to deal with other emergencies such as environmental emergencies and should be designed to do so.

\section{Developing and implementing national strategies}

Strategies to mitigate the impacts of natural hazards require planning and building to withstand a hazard, identifying and avoiding the sites where a hazard is likely, predicting the occurrence of a hazard, and preventing or altering a hazards' characteristics. These strategies are effected through land-use restriction, building codes, public awareness campaigns, emergency preparedness programs, insurance and taxation policies, and many other elements of political and economic systems. Thus, national strategies for coping with natural disasters involve scientists, engineers, planners, economists, politicians, and so forth. The necessity of obtaining contributions from this broad cross section of skills and institutions at country level underlines the key role that national IDNDR committees should play in the implementation of the Decade.

The implementation of disaster-mitigation strategies inevitably involves allocation of financial and human resources that are always in short supply. Cost-benefit analyses, therefore, are a consideration in determining whether to apply mitigation measures and in choosing between such measures. National strategies must assure that consideration is given to the long-term benefits to development versus the direct and indirect economic costs of natural disasters, as compared with the additional costs that may be involved.

\section{Applying science and technology}

Although the measures necessary to mitigate the impacts of natural disasters are implemented through national political and economic systems, their basis derives from science and technology. Effective mitigation measures require an adequate understanding of the fundamental causes of natural disasters, of the nature of their effects, and of techniques for coping with the effects. Such an understanding continually evolves as new scientific knowledge and engineering techniques develop. Thus, encouraging research and development and bringing to bear its results are integral aspects of the Decade.

The hazards encompassed by the Decade are varied in nature, and their study involves the scientific disciplines of geology, hydrology, meteorology, biology, botany, medicine, and others. Thus, in the research realm, studies of natural hazards to some extent are pursued independently. Application of the broad spectrum of scientific interests, however, has several common elements typically involving risk assessment, monitoring, and warning. Risk assessment requires knowledge of the frequency of occurrence of hazards and the nature and extent of their effects. Monitoring requires the deployment of instruments or observers and the systematic documentation of hazard phenomena. And warning requires an analysis process and communication system for determining when threatening conditions exist and when defensive actions are necessary.

One of the essential objectives of the Decade, particularly a function of the Scientific and Technical Committee, is to identify gaps in knowledge about natural hazards in order to focus research and development and to determine needs with respect to application of mitigation measures, particularly the needs of developing countries for additional financial resources and transfer of technology. Coupled with this objective is the absolute necessity of education and training of the scientists and engineers who must carry out this work.

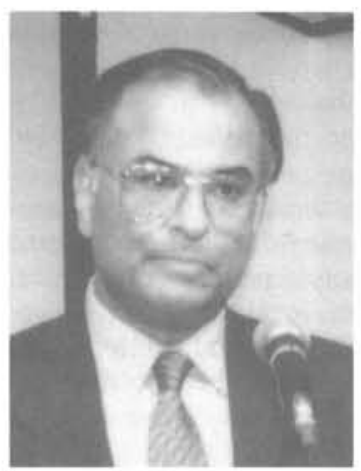

Neelam $S$. Merani is a graduate in Economics from the London School of Economics and has carried out postgraduate studies in International Law at the Indian School of International Studies. He has held a series of senior positions at the UN involved in Environmental Activities, most recently Director for Policy Development and External Relations at the UN Environmental Program. Mr. Merani served as Director of the IDNDR Secretariat from June 1990 until May 1991 . 